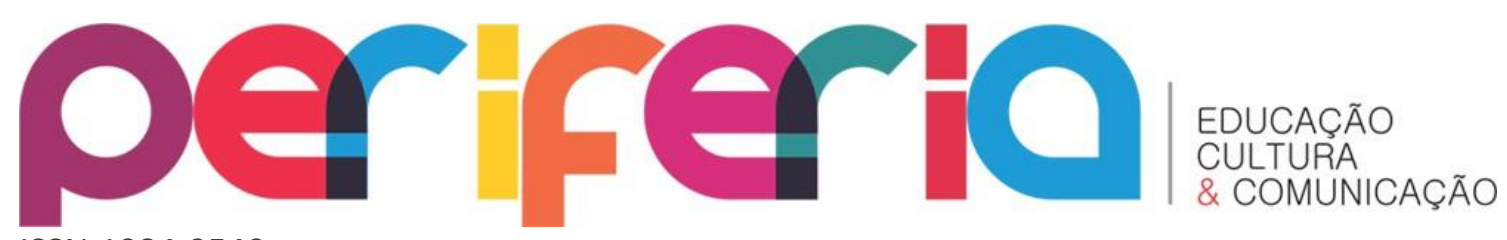

ISSN:1984-9540

\title{
MEMETIZANDO: EXPERIMENTAÇÕES COTIDIANAS EM TEMPO DE CIBERCULTURA
}

\author{
Felipe da Silva Ponte de Carvalho' \\ Rosemary dos Santos ${ }^{2}$
}

O Programa de Pós-Graduação em Educação, Cultura e Comunicação - PPGECC é uma experiência pioneira na Baixada Fluminense. Um Mestrado em Educação que assume o compromisso com o desenvolvimento de investigações voltadas para as problemáticas das periferias, sejam elas territoriais, políticas, sociais e/ou culturais e comunicacionais.

Com esse objetivo, ao longo dos anos, o Programa tem investido na formação de novos quadros intelectuais engajados no enfrentamento das questões educacionais e culturais em periferias urbanas, concebidas como lócus de produção de conhecimento e de intervenção no social que, muitas vezes, escapam aos padrões legitimados hegemonicamente.

Nessa perspectiva, a articulação entre educação, cultura e comunicação tem sido buscada a partir do entendimento de que são aspectos constitutivos da compreensão que deve mover os esforços contemporâneos de formação de educadores para aturar nas diferentes e múltiplas esferas formativas.

Dessa forma, essa articulação implica pensar sobre os valores que vêm mudando aceleradamente as diferentes áreas sociais, políticas e econômicas a partir de ações coletivas. Mudanças essas que inspiram invenções teórico-metodológicas nas diferentes áreas do conhecimento humano. A atuação desse conhecimento hoje se materializa cada vez mais pelos usos das tecnologias digitais em rede, aqui entendidas como criação cultural, cujos usos e aplicações são definidos pela atuação

\footnotetext{
1 Doutorando no Programa de Pós-Graduação em Educação da Universidade do Estado do Rio de Janeiro (ProPEd/UERJ). Membro do Grupo de Estudos em Gênero e Sexualidade e(m) Interseccionalidades (Geni) e do Grupo de Pesquisa Docência e Cibercultura (GPDOC). Bolsista FAPERJ. Orcid: http://orcid.org/0000-0001-7398-6171 E-mail: felipesilvaponte@gmail.com

2 Formada em Letras e Pedagogia. Doutora e Mestre em Educação pela UERJ. Professora Adjunta do Departamento de Formação de Professores da Faculdade de Educação da Baixada Fluminense (FEBF UERJ). Professora do Programa de Pós-Graduação em Educação, Cultura e Comunicação em Periferias Urbanas (PPGECC) na Linha de Pesquisa: Educação, Comunicação e Cultura.
} 


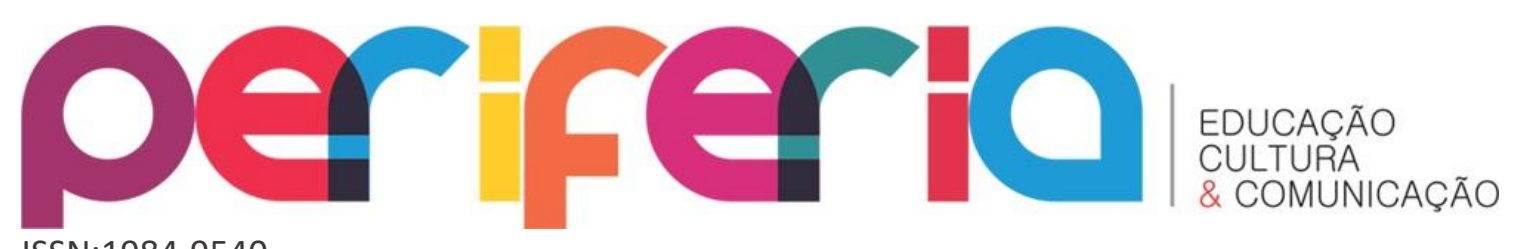

ISSN:1984-9540

direta dos sujeitos no momento sócio-histórico em que vivem, compartilham, cocriam e interagem criando múltiplas linguagens e sobretudo, ampliando seus repertórios culturais.

Assim, a Revista Periferia tem a preocupação permanente de ampliar os percursos do discurso científico, levando-os para além dos muros da universidade, em amplo diálogo com a sociedade. Para isso, contamos com nossos leitores como interlocutores com suas vozes ampliadas, nas trocas de saberes tão necessárias para escaparmos das lógicas que cada vez mais tentam restringir às dinâmicas vividas nos mais diversos espaços e tempos da sociedade. Nesse número, a Revista reitera a necessidade do amplo diálogo que devemos estabelecer com professores e estudantes.

Em um momento tão difícil que atravessamos, no Brasil e no mundo, com retrocessos nas políticas públicas, é preciso firmar compromissos com a democracia. Parte fundamental desse compromisso é ampliar o debate a partir de fontes plurais e representativas como nos textos trazidos pelos autores que colaboram conosco nesta nova edição.

O número atual da Revista Periferia “Memetizando: experimentações cotidianas em tempo de cibercultura" traz um conjunto de artigos que visam contribuir para os debates sobre a necessidade de se rediscutir estereótipos, novas fronteiras, novas formas de pensar as múltiplas linguagens criadas e inspiradas pelos usos das tecnologias digitais em redes em tempos de cibercultura, e, sobretudo, contribuir para iniciativas de diversidades temáticas, de problematizações culturais, de proposições teóricas que circulam no âmbito da Educação, exercícios de experimentação típicos de um campo sempre em construção. O termo MEME é bastante conhecido e utilizado na internet, principalmente nas redes sociais, referindo-se ao fenômeno de viralizar(quando a informação espalha-se rapidamente) entre os usuários, ou seja, qualquer vídeo, imagem, frase, ideia, música que se espalhe alcançando muita popularidade.

Para (SANTOS, COLACIQUE E CARVALHO, 2016) os memes criados na internet podem ser entendidos como aspectos da realidade imagética e trazem com humor, elementos para a imaginação que recria e interpreta a realidade por ele 


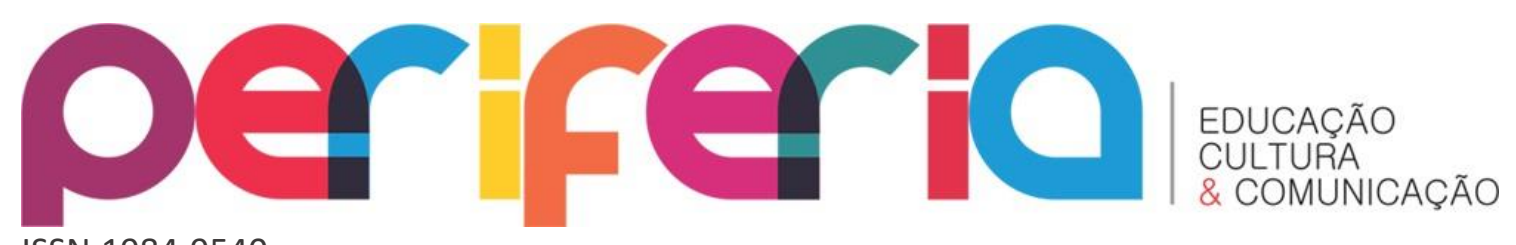

ISSN:1984-9540

representada. É, portanto, nesse contexto que o memes passam a representar o conceito, forma e estética que conhecemos hoje de forma tão difundida nas diferentes redes educativas. Retirados de imagens, desenhos, filmes e propagandas eles recriam e reproduzem situações e elementos da cultura popular em tom cômico, satírico e crítico quebrando tabus e abrindo espaços de discussão e reflexão.

Optamos, portanto, por reconhecer e valorizar todas essas experiências formativas que podem ser concebidas pelas imagens obtidas nos espaços que articulam o ciberespaço em diversos contextos sociais, buscando inferir nessa prática uma reflexão inspiradora capaz de modificar nossa prática docente.

Utilizando-nos do potencial marcante das imagens, tomando emprestada a dinâmica e a discursividade dos memes em associação com os aplicativos de produção e publicação que na sociedade contemporânea fazem emergir práticas pedagógicas e experimentações cotidianas inspiradas nos conceitos de mobilidade, interatividade, ubiquidade e conectividade, princípios que se baseiam a cultura digital para a construção do conhecimento em rede.

No artigo "ENSINAR-APRENDER COM OS MEMES: QUANDO AS ESTRATÉGIAS DE SUBVERSÃO E RESISTÊNCIA VIRALIZAM NA INTERNET", os autores Dilton Ribeiro Couto Junior, Fernando Pocahy e Felipe da Silva Ponte, exploram a forma como os memes podem constituir-se enquanto potentes estratégias contemporâneas de subversão e resistência às normas que regulam/governam corpos, gêneros e sexualidades. Para os autores a infraestrutura técnica do ciberespaço possibilita que uma quantidade significativa de usuárias/os hoje possa (co)criar, "curtir" e compartilhar amplamente informações dos mais variados tipos (imagens, vídeos, sons etc) para outras pessoas geograficamente dispersas.

Já no artigo "MEMES, RACISMO E EDUCAÇÃO, OU POR QUE OS MEMES DA TAÍS ARAÚJO IMPORTAM", Leonardo Fraga Cardoso Junior, Kaio Eduardo de Jesus Oliveira e Cristiane de Magalhães Porto discutem a importância dos memes de redes sociais digitais na Cibercultura e como eles favorecem a reprodução de discursos racistas na internet. Para isso, tomaram como objeto o caso dos memes racistas que tencionam o debate sobre racismo a partir da fala da atriz brasileira Taís Araújo em uma edição do TEDx Brasil. A produção de memes articuladas a este caso específico, insere os 


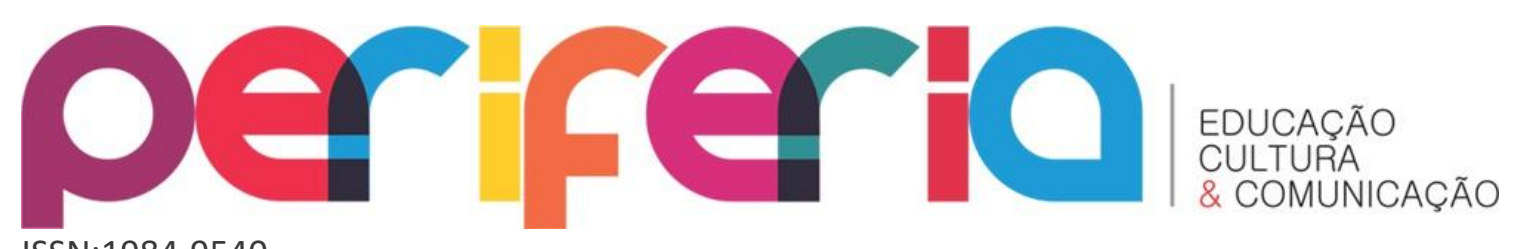

ISSN:1984-9540

usuários no debate sobre preconceito social e racial no Brasil a partir de uma fala própria que se expande na rede, especialmente permeada pelo humor e pela sátira de cada meme, mas é ampliada a partir do contexto ético e moral que toma a repercussão.

No artigo "A DISCURSIVIDADES DOS MEMES - MEMETIZANDO-SE NAS REDES EDUCATIVAS", Wallace Carriço de Almeida, Rosemary dos Santos de Oliveira e Edméa Oliveira dos Santos apresentam resultados fruto da pesquisa que ocorreu no âmbito da disciplina Informática na Educação, do curso de Pedagogia a distância da UERJ, oferecida em parceria com a Fundação Centro de Ciências e Educação Superior a Distância do Estado do Rio de Janeiro (Cecierj) / Consórcio CEDERJ durante o segundo semestre do ano de 2017. Apresentam narrativas e imagens que surgiram durante a pesquisa, verificando nelas a manifestação da autoria dos praticantes na produção crítica de memes e produzindo novos contextos de aprendizagem significativa.

No artigo "EDUCAÇÃO MUSEAL NA CIBERCULTURA: O USO DE MEMES NO PROJETO “CLUBE DE JOVENS CIENTISTAS” DA SEÇÃO DE ASSISTÊNCIA AO ENSINO (SAE) DO MUSEU NACIONAL/UFRJ", as autoras Frieda Maria Marti e Andrea Costa objetivaram narrar a experiência de criação de memes por estudantes durante uma atividade educativa da Seção de Assistência ao Ensino do Museu Nacional (MN), discutir os possíveis conhecimentossignificações que emergiram a partir destas autorias e as potencialidades educativas dos memes na educação museal. As autoras buscaram refletir sobre o contexto da educação museal na cibercultura e a relação entre ciência e sociedade.

Leonardo Nolasco-Silva, Maria da Conceição Silva Soares e Vittorio Lo Bianco, no artigo "OS MEMES E O GOLPE", sugerem pensar os memes como discursos abertos e colaborativos, capazes de participar da narração da nossa história comum, sublinhando sua potência na criação do pensamento. Para os autores, memes são discursos (imagens, vídeos, músicas e outras formas de comunicação) que viralizam na internet e despertam o desejo de atualização. Diferente do viral que se assenta basicamente no compartilhamento, o meme demanda ser modificado para se inserir em cada novo ato de compartilhar. 


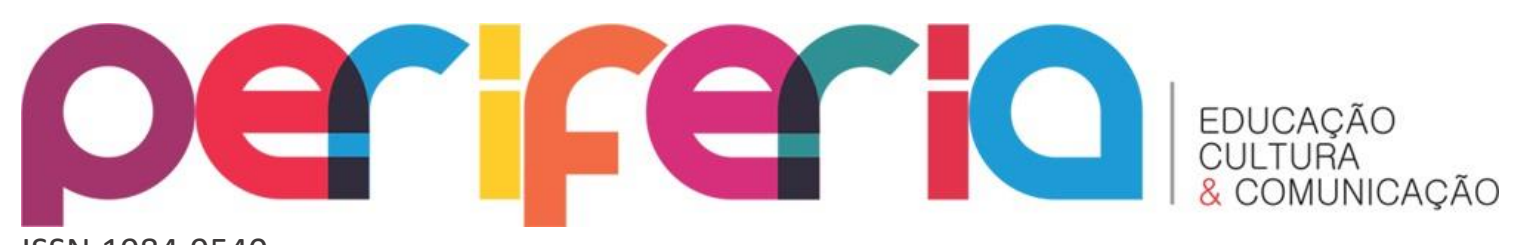

ISSN:1984-9540

0 artigo "MEMES NA INTERNET: ENTRELAÇAMENTOS ENTRE A "ZOEIRA" DE ESTUDANTES E A APROPRIAÇÃO DO GÊNERO DISCURSO NA ESCOLA" de Douglas de Oliveira Calixto, visou o reconhecimento dos memes na internet como uma linguagem articuladora dos sentidos no interior da escola. Para além de mera brincadeira ou montagens que circulam nas redes sociais, o autor procurou demonstrar como os memes representam uma nova forma de se relacionar com a comunicação e com a cibercultura.

Em “BRACE YOURSELVES, THE ZUERA IS COMING': MEMES, LETRAMENTO MIDIÁTICO DIGITAL E APROPRIAÇÃO CRIATIVA DOS FÃS DE GAME OF THRONES NO FACEBOOK", Luana Inocêncio e Davi Rebouças analisaram os diálogos intertextuais nos memes em comentários da página Game of Thrones da Depressão no Facebook, que utilizaram o humor para estruturar coletivamente uma experiência lúdica de consumo, letramento e ressignificação com relação ao produto cultural. A partir de um conjunto de termos e metáforas que são frequentemente referenciados nestes memes da série, um imaginário específico é compartithado, reconhecido e intensamente apropriado pelos interagentes, constituindo uma rica amostra da intimidade dos fãs com o universo narrativo do programa.

"AS AVENTURAS DE PAULO FREIRE CONTRA O MEME EGOÍSTA: A LUTA DE CLASSES NAS REDES SOCIAIS" os autores Aristóteles de Paula Berino, Marcélia Amorin Cardoso, Vanessa Rodrigues de Souza e Lívia Herdade discutem como Paulo Freire e o seu legado são expressos através dos memes publicados em redes sociais na internet. Destacam, ainda o sentido político dos memes que são ofensivos a Paulo Freire, descaracterizando sua obra além de insultar a sua pessoa. Os exemplares de memes que utilizaram foram extraídos das redes sociais Facebook e Twitter. Richard Dawkins e sua formulação original sobre os memes foram referências para o artigo.

Edna Araujo dos Santos de Oliveira e Roseli Zen Cerny apresenta as experiências realizadas em encontros presenciais realizados numa Semana Acadêmica de um Curso de Pedagogia. 0 foco do artigo foi a oficina "Consumo e Infância", cujo trabalho se desdobrou no espectro da cultura digital e a avaliação da aprendizagem onde foi aferida a teoria de Recouer com a elaboração de memes educativos e buscando uma compreensão crítica do o fazer docente na modalidade 


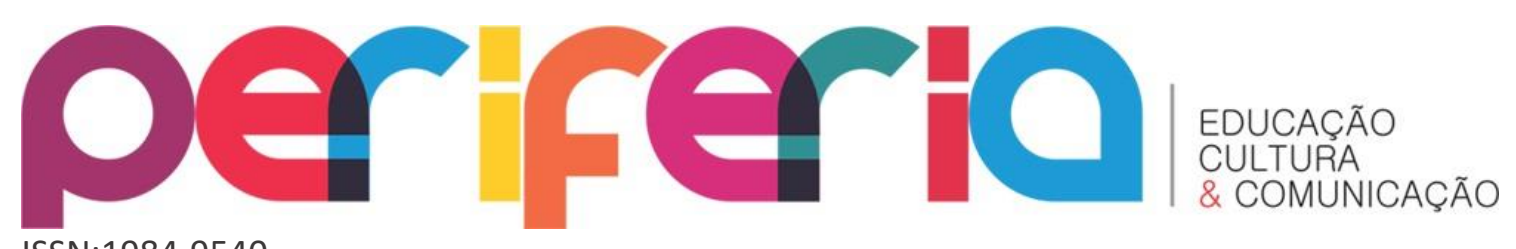

ISSN:1984-9540

a distância no artigo " SEMANA ACADÊMICA DO CURSO DE PEDAGOGIA: MEMES EM PROL DA INFÂNCIA PARA CRITICAR O CONSUMISMO".

No artigo "UMA ANÁLISE DISCURSIVA DE MEMES DO ENEM 2015", Marcia lone Surdi e Andressa Cristina Oliveira da analisam a produção de sentido dos discursos mêmicos que circulam nas redes sociais, e, específicos e a ocorrência da noção de intertexto na materialidade digital meme. As autoras procuram compreender as condições de produção dessas discursividade e a produção de sentido produzida pelos “memes" no Enem de 2015.

O artigo "MULTIMODALIDADE E EFEITOS DE SENTIDO NO GÊNERO MEME" de Josiane Brunetti Cani, considera a importância de compreender a natureza constitutiva dos gêneros influenciada pelos recursos tecnológicos digitais e tem como objetivo discutir a multimodalidade presente no gênero meme. A partir de uma análise multimodal à luz dos pressupostos teóricos abordados por Jewitt e Hiippala, apresenta alguns memes coletados no Facebook, estabelecendo uma taxonomia desses autores para a análise da multimodalidade relacionada aos principais usos desse gênero como dinâmica social.

A autora Daniele Santana de Melo, no artigo "MEMES E A EDUCAÇÃO DE JOVENS E ADULTOS" aborda os memes no contexto educacional em um estudo de caso desenvolvido na disciplina de Educação de Jovens e Adultos (EJA), em uma Faculdade da rede privada, localizada em Coronel João Sá - Bahia. O objetivo geral foi apresentar os memes através de suas potencialidades de interpretações das informações dos alunos e ex-alunos da modalidade Educação de Jovens e Adultos. Acrescido a isso, a autora mostra as concepções dos alunos e ex-alunos da EJA, e com base nas informações reconfigurar a prática docente, apontando quais os tipos de memes que podem contribuir na/para ações pedagógicas.

Já o autor Eddie Francisco Manoel Ferreira Orsini, a partir do artigo "EDUCAÇÃO, MEMES E A CATEGORAI TRABALHO”, investigou o uso de memes e outros elementos gráficos como recurso didático nesse ambiente de dificuldades e desafios que passa educação, sobretudo os colégios estaduais. Com isso, buscando construir um modus operandi para o uso da imagem (tão presente na sociedade), mas sem que 


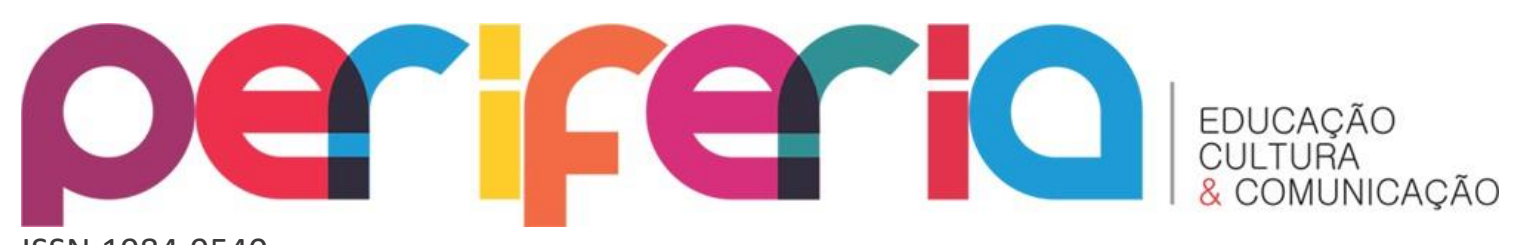

ISSN:1984-9540

se perca a riqueza do conteúdo da disciplina. Nesta pesquisa, o autor usou a teoria e método de István Mészáros, mas com a presença de outros momentos do marxismo.

Isnalda Berger e Úrsula Cunha Anecleto, no trabalho de sobre “MEMES DE IINTERNET NAS AULAS DE LÍNGUA PORTUGUESA: ALGUMAS ALTERNATIVAS PARA $O$ ESTUDO DE GÊNERO", discutemsobre memes de internet enquanto gêneros textuais híbridos que circulam em novas esferas públicas, a partir das Tecnologias da Informação e Comunicação e analisam alternativas de estudo dos memes nas aulas de Língua Portuguesa da educação básica. As autoras reforçam que, enquanto textos sócio-historicamente situados, os memes de internet, além de contribuir para a difusão de informações no espaço virtual, oportuniza a formação de opiniões e a promoção de debates nas salas de aula da educação básica, estimulando de maneira criativa a atuação de estudantes em esferas públicas digitais.

Na seção “Entrevista”, a autora Diene Eire de Mello entrevista a Prof. Dra Adriana Rocha Bruno sobre a temática "MEME E EDUCAÇÃO”, trazendo múltiplas problematizações e tensões do uso dos memes e seus desdobramentos para as práticas educativas contemporâneas.

Ainda para esta edição, trazemos na Seção de "Fluxo Continuo" o artigo “CIBERLEITURA NA EDUCAÇÃO BÁSICA: REALIDADE POSSíVEL?” das autoras Bruna Rafaela Evangelista de Oliveira e Mayra Rodrigues Fernandes Ribeiro, no qual discutem a leitura na cibercultura com base em uma pesquisa desenvolvida na Escola Estadual Antônio Gomes com alunos do $5^{\circ}$ ano do ensino fundamental. As autoras concluem que as práticas de leituras com uso das tecnologias digitais não são uma solução linear para os problemas de aprendizagens de leitura e escrita na escola, mas quando mediadas e intencionais possibilitam uma motivação e uma melhora gradativa na comunicação e produção de textual pelos alunos da educação básica.

“UMA BREVE DESCRIÇÃO SOBRE A CIBERCULTURA DOS HUE BR”, artigo de Weslley Kozlik Silva, Jamile Santinello e Graziella Medeiros Guadagnini destacam que a internet é um espaço que há algum tempo tem promovido interações entre pessoas das mais diversas partes do mundo. O objetivo do trabalho foi analisar e descrever uma cultura específica, criada nesse espaço, chamada Hue br. Os resultados desse trabalho apontam para uma construção da cibercultura a partir de resistências às 


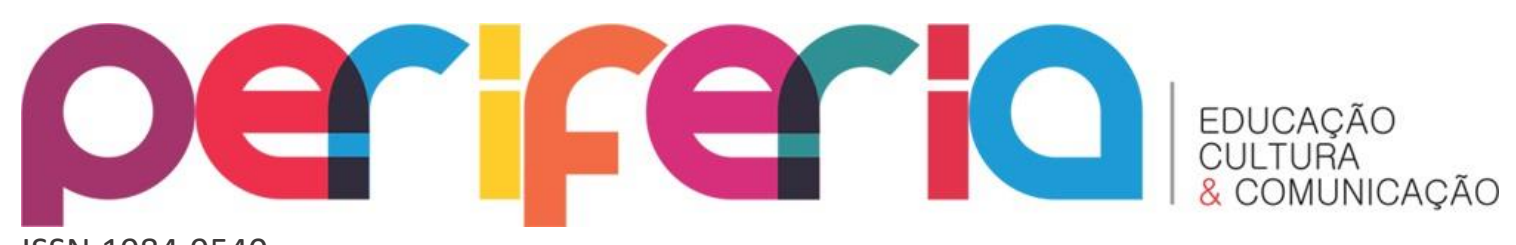

ISSN:1984-9540

imposições de jogadores de outras nacionalidades, principalmente relacionada ao idioma falado nos servidores de jogos online.

No artigo "A ETNOGRAFIA DA ESCOLA: ENTRELAÇANDO VOZES, SUJEITOS CONHECIMENTOS E CULTURAS" de Luís Paulo Cruz Borges e Paula Almeida de Castro é discutido a relação dos sujeitos da escola com o conhecimento e a cultura, analisados na perspectiva etnográfica. Para isso, os autores lançam mão dos usos da observação participante, do diário de campo, de entrevistas etnográficas e de produção textual. Por fim, propõem uma discussão crítico-reflexiva sobre os saberes e fazeres percebidos a partir dos sentidos atribuídos pelos sujeitos da educação à ação pedagógica tomando a etnografia como abordagem teórica-metodológica possível de fazer emergir as vozes silenciadas presentes no contexto escolar.

Daniel Vieira Silva, no artigo "CAMINHOS POSSÍVEIS PARA PRODUÇÃO DE PRÁTICAS PEDAGÓGICAS NO ENFRENTAMENTO DAS VIOLÊNCIAS DE GÊNERO E SEXUALIDADE", investigou as possibilidades, desafios e potências na produção de práticas pedagógicas voltadas para a discussão das temáticas relacionadas à gênero e sexualidade no espaço escolar. A partir dos relatos e experiências de quatro professoras da rede municipal de Nova Iguaçu, município da região metropolitana do estado do Rio de Janeiro, o autor destaca que foi possível perceber elementos que diferenciam as práticas produzidas por essas professoras a partir do olhar atento para as questões de violência, marginalização e produção de desigualdade frente às percepções e performances de gênero e sexualidade.

\section{REFERÊNCIAS}

ALMEIDA, Wallace Carriço de; SANTOS, Rosemary dos; e SANTOS, Edméa Oliveira. A discursividades dos memes - Memetizando-se nas redes educativas. Revista Periferia, v. 11, n. 2, 2019, p. 57-89. DOI: <https://doi.org/10.12957/periferia.2019.39246>.

BERINO, Aristóteles de Paula; CARDOSO, Marcélia Amorin; SOUZA, Vanessa Rodrigues de; e HERDADE, Lívia. As aventuras de Paulo Freire contra o meme egoísta: a luta de classes nas redes sociais. Revista Periferia, v. 11, n. 2, 2019, p. 178-202. DOI: < https://doi.org/10.12957/periferia.2019.37062>. 


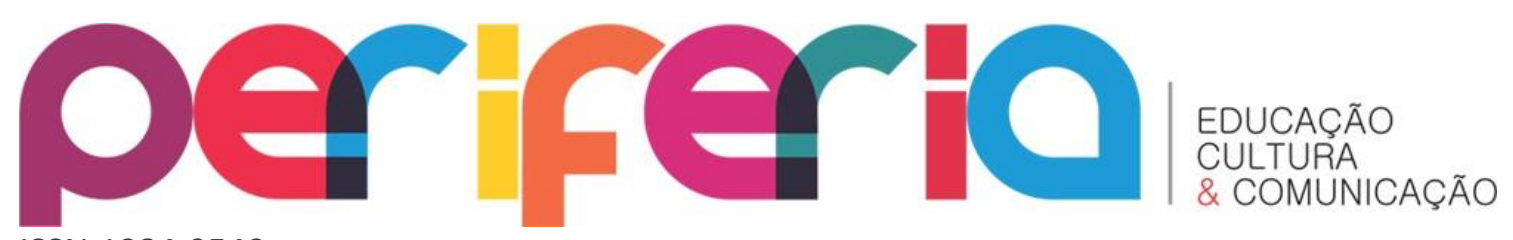

ISSN:1984-9540

BORGES, Luís Paulo Cruz; e CASTRO, Paula Almeida de. A etnografia da escola: entrelaçando vozes, sujeitos conhecimentos e culturas. Revista Periferia, v. 11, n. 2, 2019, p. 404-423. DOI: <https://doi.org/10.12957/periferia.2019.39126>.

CALIXTO, Douglas de Oliveira. Memes na internet: entrelaçamentos entre a "zoeira" de estudantes e a apropriação do gênero discurso na escola. Revista Periferia, v. 11, n. 2, 2019, p. 131-152. DOI: <https://doi.org/10.12957/periferia.2019.36457>.

CANI, Josiane Brunetti Cani. Multimodalidade e efeitos de sentido no gênero meme. Revista Periferia, v. 11, n. 2, 2019, p. 242-267. DOI: <https://doi.org/10.12957/periferia.2019.36955>.

COUTO JUNIOR, Dilton Ribeiro; POCAHY, Fernando; e CARVALHO, Felipe da Silva Ponte de. Ensinar-aprender com os memes: quando as estratégias de subversão e resistência viralizam na internet. Revista Periferia, v. 11, n. 2, 2019, p. 17-38. DOI: <https://doi.org/10.12957/periferia.2019.36180>.

INOCÊNCIO, Luana Inocêncio; e REBOUCAS, Davi. 'Brace yourselves, the zuera is coming': memes, letramento midiático digital e apropriação criativa dos fãs de Game of Thrones no Facebook. Revista Periferia, v. 11, n. 2, 2019, p. 153-177. DOI: <https://doi.org/10.12957/periferia.2019.36892>.

JUNIOR, Leonardo Fraga Cardoso; OLIVEIRA, Kaio Eduardo de Jesus Oliveira; e PORTO, Cristiane de Magalhães Porto. Memes, racismo e educação, ou por que os memes da Taís Araújo importam. Revista Periferia, v. 11, n. 2, 2019, p. 39-56. DOI: < https://doi.org/10.12957/periferia.2019.33878>.

MARTI, Frieda Maria; e COSTA, Andrea. Educação Museal na Cibercultura: o uso de memes no projeto "Clube de Jovens Cientistas" da Seção de Assistência ao Ensino (SAE) do Museu Nacional/UFRJ. Revista Periferia, v. 11, n. 2, 2019, p. 90-110. DOI: <https://doi.org/10.12957/periferia.2019.39617>.

MELLO, Diene Eire de. Meme e educação: entrevista a Prof. Dra. Adriana Rocha Bruno. Revista Periferia, v. 11, n. 2, 2019, p. 344-353. DOI: <https://doi.org/10.12957/periferia.2019.39505>.

MELO, Daniele Santana de. Memes e a educação de jovens e adultos. Revista Periferia, v. 11, n. 2, 2019, p. 268-290. DOI: <https://doi.org/10.12957/periferia.2019.36856>.

NOLASCO-SILVA, Leonardo Nolasco-Silva; SOARES, Maria da Conceição Silva; e LO BIANCO, Vittorio. Os memes e o golpe. Revista Periferia, v. 11, n. 2, 2019, p. 111130. DOI: <https://doi.org/10.12957/periferia.2019.37034>. 


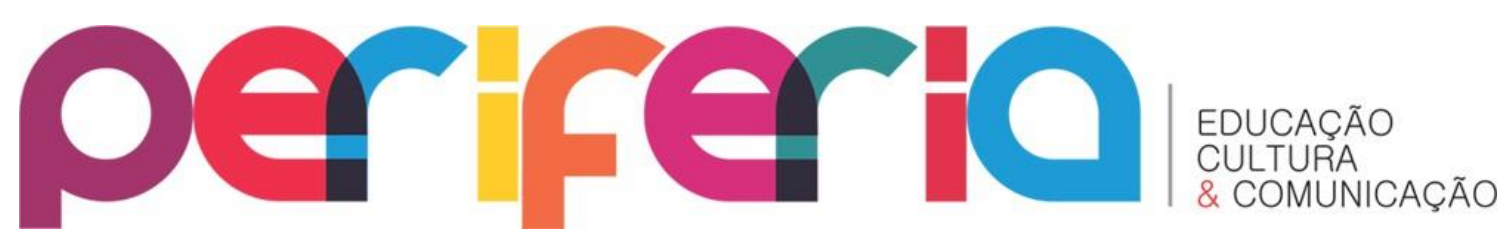

ISSN:1984-9540

OLIVEIRA, Bruna Rafaela Evangelista de; e RIBEIRO, Mayra Rodrigues Fernandes. Ciberleitura na educação básica: realidade possível? Revista Periferia, v. 11, n. 2, 2019, p. 354-383. DOI: <https://doi.org/10.12957/periferia.2019.39384>.

OLIVEIRA, Edna Araujo dos Santos de; e CERNY, Roseli Zen. Semana acadêmica do curso de Pedagogia: meme em prol da infância para criticar consumismo. Revista Periferia, v. 11, n. 2, 2019, p. 203-219. DOI: < https://doi.org/10.12957/periferia.2019.36456>.

ORSINI, Eddie Francisco Manoel Ferreira. Educação, memes e a categoria trabalho. Revista Periferia, v. 11, n. 2, 2019, p. 291-316. DOI: <https://doi.org/10.12957/periferia.2019.35086>.

SANTOS, E.; COLACIQUE, R.; CARVALHO, F. A autoria visual na internet: o que dizem os memes?. Quaestio - Revista de Estudos em Educação, v. 18, n. 1, p. p. 135-157, 13 jul. 2016.

SILVA, Daniel Vieira. Caminhos possíveis para produção de práticas pedagógicas no enfrentamento das violências de gênero e sexualidade. Revista Periferia, v. 11, n. 2, 2019, p. 424-441. DOI: https://doi.org/10.12957/periferia.2019.36363

SILVA, Weslley Kozlik; SANTILLO, Jamile; e GUADAGNINI, Graziella Medeiros. Uma breve descrição sobre a cibercultura dos HUE BR. Revista Periferia, v. 11, n. 2, 2019, p. 384-403. DOI: < https://doi.org/10.12957/periferia.2019.33505>.

SURDI, Marcia lone; e OLIVEIRA, Andressa Cristina. Uma análise discursiva de memes do ENEM 2015. Revista Periferia, v. 11, n. 2, 2019, p. 220-241. DOI: <https://doi.org/10.12957/periferia.2019.36362>. 